\title{
Binaural Interactions Develop in the Auditory Brainstem of Children Who Are Deaf: Effects of Place and Level of Bilateral Electrical Stimulation
}

\author{
Karen A. Gordon, ${ }^{1,2}$ Claire Salloum, ${ }^{1}$ Gurvinder S. Toor, ${ }^{1}$ Richard van Hoesel, ${ }^{3}$ and Blake C. Papsin ${ }^{1,2}$ \\ ${ }^{1}$ Archie's Cochlear Implant Laboratory, Hospital for Sick Children, Toronto, Ontario M5G 1X8, Canada 2Department of Otolaryngology-Head and Neck \\ Surgery, University of Toronto, Toronto, Ontario M5G 2N2, Canada, and ${ }^{3}$ The HEARing Cooperative Research Centre, Melbourne, Victoria 3010, Australia
}

Bilateral cochlear implants (CIs) might promote development of binaural hearing required to localize sound sources and hear speech in noise for children who are deaf. These hearing skills improve in children implanted bilaterally but remain poorer than normal. We thus questioned whether the deaf and immature human auditory system is able to integrate input delivered from bilateral CIs. Using electrophysiological measures of brainstem activity that include the Binaural Difference (BD), a measure of binaural processing, we showed that a period of unilateral deprivation before bilateral CI use prolonged response latencies but that amplitudes were not significantly affected. Tonotopic organization was retained to some extent as evidenced by an elimination of the BD with large mismatches in place of stimulation between the two CIs. Smaller place mismatches did not affect BD latency or amplitude, indicating that the tonotopic organization of the auditory brainstem is underdeveloped and/or not well used by CI stimulation. Finally, BD amplitudes decreased when the intensity of bilateral stimulation became weighted to one side and this corresponded to a perceptual shift of sound away from midline toward the side of increased intensity. In summary, bilateral CI stimulation is processed by the developing human auditory brainstem leading to perceptual changes in sound location and potentially improving hearing for children who are deaf.

\section{Introduction}

Children who are deaf can hear and develop spoken language using cochlear implants (CIs) which electrically stimulate the auditory nerve. Unfortunately, they struggle to hear in noise for many reasons which could include inadequate access to binaural cues. Normally, sound from one source arrives at the two ears at slightly different times or levels but with similar frequency content. These timing and level differences are coded in the superior olive of the auditory brainstem allowing auditory signals to be separated by their relative spatial positions (McAlpine, 2005; Akeroyd, 2006). Interaural timing cues are particularly helpful for detecting speech in noise and attending to one sound source among many (Hawley et al., 2004; Akeroyd, 2006; Schnupp and Carr, 2009) but might be disrupted by two independently functioning CIs which are unable to convey fine timing information in speech. This leaves CI users with abnormal perception of binaural timing cues (van Hoesel, 2007; Litovsky et al., 2010; Salloum et al., 2010) and a reliance on interaural level cues for binaural processing. We asked whether these sound cues can be

\footnotetext{
Received Nov. 16, 2011; revised Jan. 26, 2012; accepted Feb. 1, 2012.

Author contributions: K.A.G. and C.S. designed research; K.A.G., C.S., and B.C.P. performed research; R.v.H. contributed unpublished reagents/analytic tools; K.A.G., C.S., and G.S.T. analyzed data; K.A.G., C.S., G.S.T., and R.v.H. wrote the paper.

Funding was provided by the Canadian Institutes of Health Research (MOP-89804). We acknowledge the children and families who participated in this study as well as the Cochlear Implant Team at the Hospital for Sick Children.

Correspondence should be addressed to Dr. Karen A. Gordon, CCC-A, Reg. CASLPO, The Hospital for Sick Children, Room 6D08, 555 University Avenue, Toronto, 0N M5G 1X8, Canada. E-mail: karen.gordon@utoronto.ca.

DOI:10.1523/JNEUROSCI.5741-11.2012

Copyright $\odot 2012$ the authors $\quad 0270-6474 / 12 / 324212-12 \$ 15.00 / 0$
}

detected by the immature deaf auditory pathways in pediatric CI users.

Bilateral electrical input to the mature auditory brainstem and midbrain through two CIs provides some of the binaural cues necessary for sound localization (Smith and Delgutte, 2007a,b; He et al., 2010) but these cues could be further distorted by immaturity or reorganization of binaural pathways due to childhood deafness (Schwartz and Higa, 1982; Lee et al., 2001). Unilateral CI use, while promoting development along the auditory pathways in children who are deaf (Gordon et al., 2003, 2005, 2006, 2008), could disrupt binaural processing by strengthening only those pathways coming from the implanted ear. It is clear that unilateral deprivation in early life through amblyopia (visual impairment in one eye) (Wiesel and Hubel, 1963, 1965; Hubel and Wiesel, 1970; Mower, 1991) or "amblyotia" (hearing impairment in one ear) (Silverman and Clopton, 1977; McAlpine et al., 1997; Vale et al., 2004) causes abnormal strengthening of the stimulated side which may not be reversible if it extends beyond a sensitive period.

In the present study, we evaluated binaural processing in CI recipients with inter-implant variations in place and level of stimulation. Although previous studies of normal human binaural processing have used magnetic resonance imaging of the inferior colliculus (Thompson et al., 2006), this technique is contraindicated for CI users (Majdani et al., 2008). Binaural interaction can also be studied using electrophysiology as shown in normal hearing individuals (Wada and Starr, 1989; Furst et al., 1990; Jiang and Tierney, 1996; Goksoy et al., 2005) as well as bilateral CI users (adults: He et al., 2010; children: Gordon et al., 2007a; cats: Smith 
Table 1. Demographic information and device details for all participants

\begin{tabular}{|c|c|c|c|c|c|c|c|c|c|c|c|c|c|c|c|c|}
\hline \multirow[b]{2}{*}{ Child } & \multirow[b]{2}{*}{ Onset of deafness } & \multirow[b]{2}{*}{ Etiology } & \multicolumn{3}{|l|}{$\mathrm{Cl} 1$} & \multicolumn{2}{|l|}{$\mathrm{Cl} 2$} & \multirow[b]{2}{*}{ Unilateral Cl experience } & \multicolumn{4}{|c|}{ Bilateral experience } & \multicolumn{4}{|c|}{ Age at test } \\
\hline & & & Age & Ear & Device & Age & Device & & A & $B$ & $C$ & D & A & B & $C$ & D \\
\hline 1 & Congenital & Unknown & 0.8 & Right & $24 C S$ & 3.7 & $24 \mathrm{CA}$ & 3.0 & & 3.1 & 2.7 & 4.6 & & 6.8 & 6.4 & 8.3 \\
\hline 2 & Congenital & Connexin 26 & 1.0 & Right & $24 C A$ & 1.7 & $24 \mathrm{CA}$ & 0.7 & & 2.1 & 1.6 & & & 3.8 & 3.3 & \\
\hline 3 & Congenital & Unknown & 3.8 & Right & $24 \mathrm{M}$ & 9.6 & $24 C S$ & 5.8 & & 2.7 & 2.7 & 4.0 & & 12.3 & 12.3 & 13.6 \\
\hline 4 & Congenital & Connexin 26 & 3.9 & Right & $24 \mathrm{M}$ & 9.5 & $24 \mathrm{CA}$ & 5.6 & & 2.5 & 2.2 & & & 12.0 & 11.8 & \\
\hline 5 & Congenital & Connexin 26 & 1.6 & Right & $24 \mathrm{M}$ & 6.9 & $24 \mathrm{CA}$ & 5.3 & & 2.2 & 2.1 & 4.1 & & 9.2 & 9.1 & 11.1 \\
\hline 6 & Congenital & Unknown & 1.2 & Right & $24 C A$ & 2.1 & 24RE & 1.0 & & 2.0 & 1.7 & & & 4.1 & 3.9 & \\
\hline 7 & Congenital & Unknown & 1.3 & Right & $24 C S$ & 3.9 & $24 C S$ & 2.6 & & 3.3 & & & & 7.2 & & \\
\hline 8 & Congenital & Unknown & 1.9 & Right & $24 C S$ & 4.5 & 24RE & 2.5 & & 0.7 & 0.6 & 1.9 & & 5.1 & 5.0 & 6.4 \\
\hline 9 & Progressive & Unknown & 2.9 & Right & 24RE & 2.9 & 24RE & 0.0 & & 1.5 & 0.7 & & & 4.5 & 3.6 & \\
\hline 10 & Congenital & Leopard syndrome & 5.4 & Right & $24 \mathrm{M}$ & 10.8 & $24 C S$ & 5.4 & & 3.0 & 2.9 & & & 13.8 & 13.7 & \\
\hline 11 & Congenital & Connexin 26 & 0.9 & Right & $24 \mathrm{CA}$ & 1.9 & 24RE & 1.0 & & 1.3 & & & & 3.2 & & \\
\hline 12 & Congenital & Unknown & 0.9 & Right & $24 C S$ & 3.5 & 24RE & 2.6 & & 0.8 & 0.5 & & & 4.3 & 4.0 & \\
\hline 13 & Congenital & Unknown & 2.2 & Right & $24 M$ & 10.0 & 24RE & 7.8 & 3.2 & 1.2 & 0.9 & 2.3 & 13.1 & 11.2 & 10.9 & 12.3 \\
\hline 14 & Congenital & Connexin 26 & 2.1 & Right & $24 C S$ & 5.9 & 24RE & 3.8 & & 1.1 & 0.9 & & & 7.0 & 6.8 & \\
\hline 15 & Congenital & Connexin 26 & 1.9 & Right & $24 C S$ & 5.1 & 24RE & 3.2 & & 1.6 & 2.0 & 2.1 & & 6.7 & 7.1 & 7.2 \\
\hline 16 & Congenital & Unknown & 1.0 & Right & $24 C S$ & 4.5 & 24RE & 3.5 & & 1.1 & 1.0 & 2.4 & & 5.6 & 5.5 & 6.9 \\
\hline 17 & Congenital & Connexin 26 & 1.7 & Right & $24 C S$ & 5.5 & 24RE & 3.8 & & 1.2 & 1.0 & & & 6.7 & 6.5 & \\
\hline 18 & Congenital & Waardenburg type 2 & 1.9 & Right & $24 \mathrm{CA}$ & 2.6 & 24RE & 0.7 & & & 2.5 & 3.1 & & & 5.1 & 5.7 \\
\hline 19 & Progressive & Unknown & 2.4 & Right & 24RE & 3.3 & 24RE & 0.9 & 3.5 & 1.7 & 1.1 & 2.3 & 6.9 & 5.0 & 4.4 & 5.7 \\
\hline 20 & Congenital & Unknown & 1.6 & Right & 24RE & 1.6 & 24RE & 0.0 & & 1.8 & 1.7 & & & 3.4 & 3.3 & \\
\hline 21 & Congenital & Unknown & 2.0 & Right & 24RE & 2.0 & 24RE & 0.0 & & 1.5 & 1.3 & & & 3.5 & 3.3 & \\
\hline 22 & Congenital & Connexin 26 & 2.3 & Right & 24RE & 2.3 & $24 R E$ & 0.0 & & 1.1 & 1.1 & & & 3.4 & 3.4 & \\
\hline 23 & Congenital & Usher's & 2.0 & Right & $24 \mathrm{M}$ & 10.3 & 24RE & 8.3 & & 1.0 & 1.0 & 2.1 & & 11.3 & 11.3 & 12.4 \\
\hline 24 & Congenital & Usher's & 1.0 & Right & $24 C S$ & 6.5 & 24RE & 5.4 & 3.0 & 1.1 & 1.1 & & 9.5 & 7.6 & 7.5 & \\
\hline 25 & Congenital & Connexin 26 & 1.0 & Right & 24RE & 1.0 & 24RE & 0.0 & & 1.9 & 1.4 & & & 2.8 & 2.4 & \\
\hline 26 & Congenital & Connexin 26 & 1.5 & Left & $24 \mathrm{CA}$ & 4.5 & 24RE & 3.0 & & 1.0 & 0.7 & 1.7 & & 5.4 & 5.2 & 6.2 \\
\hline 27 & Congenital & NICU & 2.8 & Right & 24RE & 3.7 & 24RE & 0.9 & & & 1.0 & & & & 4.7 & \\
\hline 28 & Congenital & Connexin 26 & 1.0 & Right & 24RE & 1.0 & 24RE & 0.0 & & 2.4 & 2.1 & & & 3.3 & 3.0 & \\
\hline 29 & Progressive & Connexin 26 & 1.0 & Right & $24 C S$ & 4.8 & 24RE & 3.8 & & 0.9 & 0.6 & 1.5 & & 5.7 & 5.4 & 6.4 \\
\hline 30 & Congenital & Connexin 26 & 2.3 & Left & $24 C S$ & 5.6 & 24RE & 3.3 & & 0.9 & 0.6 & 1.6 & & 6.5 & 6.2 & 7.2 \\
\hline 31 & Progressive & Connexin 26 & 2.9 & Right & $24 C S$ & 8.0 & 24RE & 5.1 & & & 0.5 & & & & 8.4 & \\
\hline 32 & Congenital & Connexin 26 & 0.7 & Right & $24 \mathrm{CA}$ & 1.5 & $24 \mathrm{CA}$ & 0.8 & & 2.7 & 2.6 & & & 4.2 & 4.1 & \\
\hline 33 & Congenital & Unknown & 0.9 & Right & 24RE & 0.9 & 24RE & 0.0 & & & 0.7 & & & & 1.6 & \\
\hline 34 & Congenital & Unknown & 0.9 & Right & $24 \mathrm{CA}$ & 1.7 & 24RE & 0.8 & & & 1.7 & & & & 3.4 & \\
\hline 35 & Congenital & Usher's & 0.7 & Right & 24RE & 1.6 & 24RE & 0.9 & & & 0.8 & & & & 2.5 & \\
\hline 37 & Sudden & Meningitis & 1.9 & Right & $24 C S$ & 12.9 & 24RE & 11.1 & & & 0.7 & & & & 13.6 & \\
\hline 39 & Congenital & Unknown & 3.2 & Left & $24 \mathrm{M}$ & 12.4 & 24RE & 9.2 & & & 0.7 & & & & 13.2 & \\
\hline 40 & Congenital & Connexin & 1.8 & Right & 24RE & 1.8 & 24RE & 0.0 & & & 1.3 & & & & 3.1 & \\
\hline 42 & Progressive & Unknown & 9.1 & Right & $24 C S$ & 10.9 & 24RE & 1.8 & & & 1.5 & & & & 12.3 & \\
\hline 44 & Congenital & Connexin 26 & 2.2 & Right & $24 C S$ & 7.4 & 24RE & 5.2 & & & 2.5 & & & & 9.9 & \\
\hline 45 & Congenital & Connexin 26 & 1.1 & Right & $24 \mathrm{CA}$ & 3.6 & 24RE & 2.5 & 2.2 & & & & 5.8 & & & \\
\hline 47 & Congenital & Usher's & 1.2 & Left & $24 \mathrm{CA}$ & 5.0 & 24RE & 3.8 & 3.0 & & & & 7.9 & & & \\
\hline 48 & Congenital & Unknown & 1.5 & Right & $24 C S$ & 5.8 & 24RE & 4.3 & 2.0 & & & & 7.8 & & & \\
\hline 50 & Congenital & Unknown & 1.5 & Right & 24RE & 2.5 & 24RE & 1.0 & 2.6 & & & & 5.1 & & & \\
\hline 51 & Sudden & Ototoxic drugs & 12.2 & Right & 24RE & 12.2 & 24RE & 0.0 & 0.2 & & & & 12.4 & & & \\
\hline 52 & Congenital & Unknown & 1.2 & Right & 24RE & 1.2 & 24RE & 0.0 & 1.2 & & & & 2.4 & & & \\
\hline 53 & Sudden & Meningitis & 1.7 & Right & $24 \mathrm{CA}$ & 4.8 & 24RE & 3.1 & 1.4 & & & & 6.3 & & & \\
\hline 54 & Congenital & Unknown & 1.1 & Right & 24RE & 3.3 & 24RE & 2.2 & 1.3 & & & & 4.5 & & & \\
\hline 55 & Sudden & Connexin 26 & 11.2 & Left & $24 C S$ & 16.7 & 24RE & 5.5 & 0.8 & & & & 17.5 & & & \\
\hline
\end{tabular}

The age (years), device types, onset of deafness (congenital or progressive deterioration), etiology/risk factors for hearing loss, and duration of Cl experience (years) for each participant are summarized. Duration of bilateral experience (years) and age (years) are shown for each of the 4 experiments: A, Electrophysiological effects of large mismatches in place of bilateral stimulation; B, Electrophysiological effects of small mismatches in place of bilateral stimulation; $C$, Electrophysiological responses to inter-implant level differences; and D, Behavioral responses to inter-implant level differences.

and Delgutte, 2007). Using this technique, we demonstrate that binaural processing in the brainstem of children using bilateral CIs: (1) occurs regardless of bilateral or unilateral deafness, (2) is disrupted by large but not small mismatches in place of stimulation and (3) codes perceptible changes in level cues.

\section{Materials and Methods}

Participants. A total of 49 children of either sex using bilateral cochlear implants participated in the present study. Binaural inhibition and behavioral responses to large or small mismatches in place of stimulation and mismatches in intensity of stimulation were assessed. Measures from each child included variations in at least one of these parameters. The age at testing for each set of recordings is provided for each child in Table 1.
The children used a number of different combinations of Nucleus 24 devices which included, in chronological order of device release, the 24M, 24CS, 24CA, and 24RE. These devices are described in Figure 1. All of these $\mathrm{CI}$ arrays are of equal length, have 22 stimulating electrodes and are meant to be implanted into the scala tympani of the cochlea. Highfrequency input is coded by basal electrodes stimulation with progressively lower frequencies being represented by more apical electrodes. A reference ball electrode is placed under the temporalis muscle, and a reference plate electrode is incorporated into the receiver-stimulator component that is surgically embedded on the skull (Patrick et al., 2006). Device details are provided for each child in Table 1, which also indicates demographic information for all participants including: onset of deafness; etiology of hearing loss; age at testing for each experiment (years); 


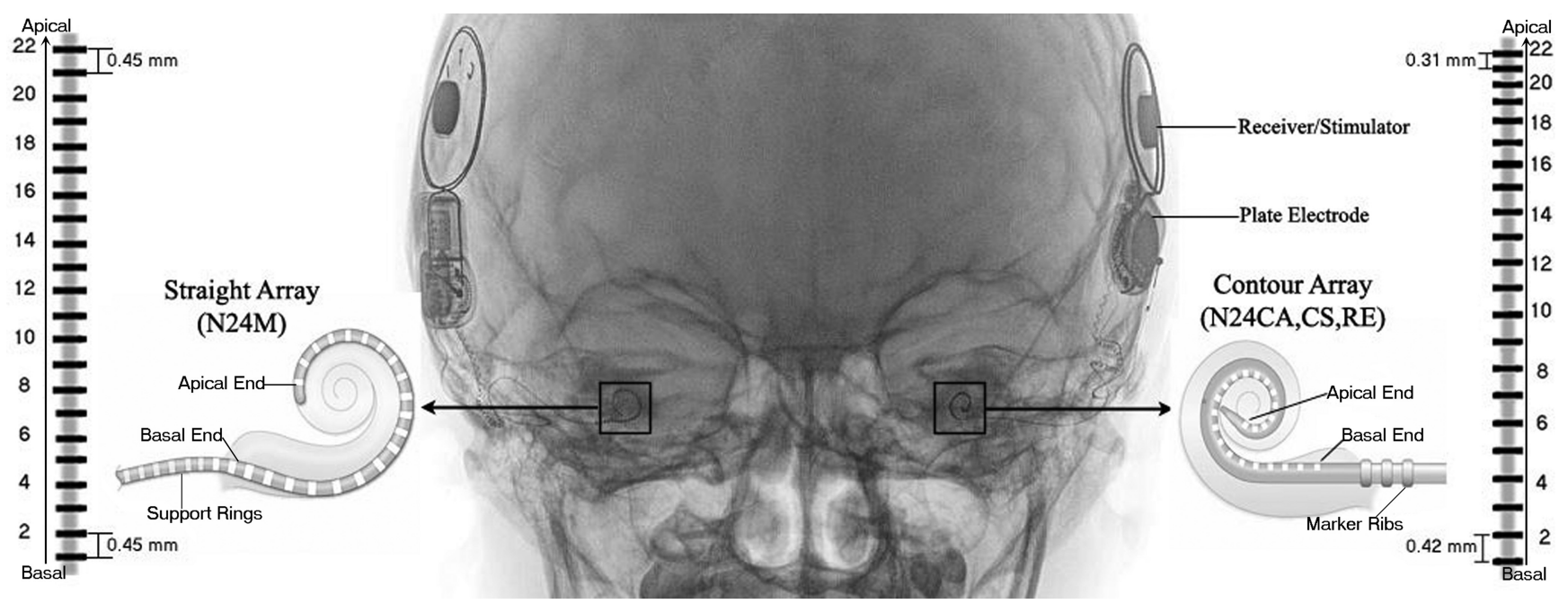

Figure 1. $x$-ray image of a child (participant 10) who received bilateral cochlear implants. Rectangles highlight the intracochlear electrode arrays. Schematics of the arrays for 2 different Nucleus 24 devices are also shown courtesy of Cochlear Ltd. (Sydney, Australia). Both arrays are the same length, with 22 stimulating electrodes, and two reference electrodes (ball electrode placed under the temporalis muscle and plate electrode placed with the receiver stimulator and embedded on the skull). However, Contour arrays are precurved to place the electrodes closer to the inner wall of the cochlea (modiolus), and thus to the primary auditory neurons, and have half banded electrodes with decreasing distance between adjacent electrodes in the apical end compared with regularly spaced full-band electrodes in the straight 24M array.

ages at implantation (years); generations of the first/right (CI1) and second/left (CI2) devices; and duration of unilateral and bilateral implant experience (years). Thirty-nine children received a second CI after using their first CI for an average of $3.62 \pm 2.51$ years (mean $\pm \mathrm{SD}$ ). Alternatively, 10 participants received both implants during the same surgery. We assigned "CI1" to the right CI and "CI2" to the left CI in children receiving bilateral CIs simultaneously for all analyses. All children had normal cochlear morphology as judged by high resolution computed tomography and magnetic resonance imaging of the temporal bones before implantation and full insertion of the CI array was achieved for each child.

Electrophysiological measures. Auditory brainstem responses were evoked by electrical pulses presented to the left and right cochlear implants separately and by pulses presented from both cochlear implants simultaneously. As shown in Figure $2 A$, the electrically evoked auditory brainstem responses (EABRs) are characterized by three positive peaks (eII, eIII, and eV) observed at latencies defined previously (Gordon et al., 2006). These peaks correspond to activity in the auditory nerve (eII), cochlear nucleus (eIII), and lateral lemniscus (eV) (Gordon et al., 2006).

Binaural interaction was measured by summing the two unilaterally evoked responses (left and right cochlear implant stimulation) and then subtracting the bilaterally evoked response from this. Although sometimes referred to as the Binaural Interaction Component or BIC, we used another commonly used term, the Binaural Difference (BD), to describe the difference measure. A typical series of responses, along with the $\mathrm{BD}$, are shown in Figure $2 B-D$. Responses were collected in 2 recording channels (Cz/A1 and $\mathrm{Cz} / \mathrm{A} 2)$ and evoked by three stimulus conditions: CI1 $(B)$, CI2 $(C)$, or both CIs $(D)$. Figure $2 E$ shows the summed response of CI1- and CI2-evoked responses (as shown in Fig. 2, $A$ and $B$, respectively). The $\mathrm{BD}$, shown in Figure $2 F$, is the difference between the summed response (as shown in Fig. 2E) and the recorded response to both CIs (as shown in Fig. 2D).

Stimulation parameters were programmed and delivered through a SPEAR processor and custom software (The HEARing CRC Melbourne, Australia). Single electrical pulses ( $25 \mu \mathrm{s} /$ phase) were delivered at a frequency of 11 pulses per second (pps). Stimulus intensities were specified using Current Units (CUs) defined by the CI manufacturer to reflect clinical practices. Conversion of microamperes to CUs differs slightly between different device generations which would make it difficult to compare data across devices and children. Therefore, for the purposes of data analysis, CUs were first converted into microamperes $(\mu \mathrm{A})$ and then into decibels $(\mathrm{dB})$ as defined by the following formula: $\mathrm{dB}=20 \log (A / B)$, where $A$ is the delivered current $(\mu \mathrm{A})$ and $B$ is $100 \mu \mathrm{A}$. Unilaterally evoked $\mathrm{eV}$ amplitude data from electrode 18 at 5 different intensity levels from 19 of the 49 children have been previously reported (Salloum et al., 2010).

Place of bilateral electrical stimulation. In animal models, input from the same cochlear location in both ears is favored for bilateral processing (Smith and Delgutte, 2007a) reflecting the importance of tonotopic representation along the bilateral pathways. In the present study, we assessed whether the expected tonotopic organization of bilateral projections affects binaural function in children who are deaf.

Bilateral stimuli were presented either from electrodes which were at the same location along the electrode array in the two cochleae or which were from mismatched locations along the array. We examined responses evoked by matched electrode positions in the apical end (\#20 and $\# 18$ ) and in the basal end (\#3). Mismatches between the two places of stimulation on the array were either very large [electrode at the apical end (\#20) on one CI and at the basal end (\#3) on the other] or were smaller (\#18 on one CI and \#14,\#16,\#20, or \#22 on the other). For these series of recordings, the intensity of electrical stimulation was adjusted to ensure that the amplitudes of the CI1 and CI2 EABRs were matched. Unilaterally delivered intensities were increased until growth of EABR wave $\mathrm{eV}$ amplitude with increases in stimulus intensity reached a plateau or until the child indicated any discomfort. Levels were adjusted on the opposite $\mathrm{CI}$ until the amplitude of wave $\mathrm{eV}$ of that response visually matched the first.

Level of bilateral electrical stimulation. The head attenuates the intensity of sound reaching the ear furthest away from the source; this "head shadow" sets up intensity differences between the ears [interaural level differences (ILDs)]. We asked whether these cues were processed in the brainstem of children who use bilateral CIs. Behavioral results and unilaterally evoked $\mathrm{eV}$ amplitudes from this protocol have been previously reported (Salloum et al., 2010).

EABRs were evoked by electrical pulses presented bilaterally and unilaterally. The range of stimulus intensities delivered by each CI was 20 CUs for each child. However, the maximum level was customized for each child to ensure that the sound was loud but comfortable. Current levels were increased for each CI until the child indicated or gave any behavioral signs (i.e., change in facial expression, increased tension in body, slower breathing rate) that the input was too loud or uncomfortable. The lower of the left and right maximum levels became the upper limit of the $20 \mathrm{CU}$ intensity range. Unilateral presentations decreased in level from this intensity in $5 \mathrm{CU}$ steps. Bilateral presentations kept the overall CU constant within the same $20 \mathrm{CU}$ range but increased the level differences between the 2 CIs from 0 to 10 and 20 CUs. Thus, if the range 


\section{RESPONSE SOURCES}

A

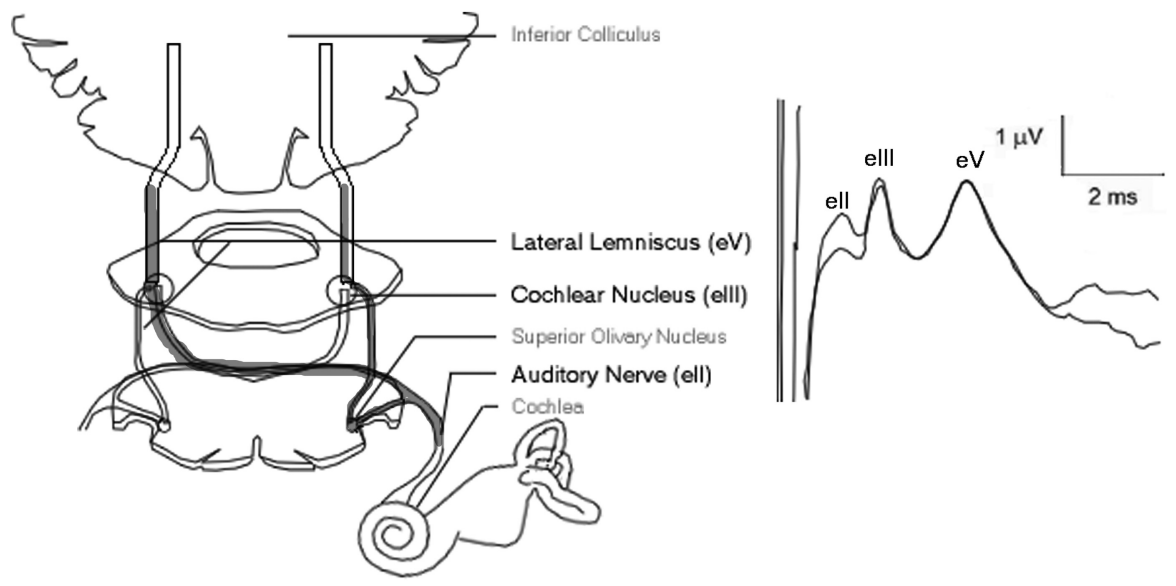

RECORDED WAVEFORMS

Recording Channel 1

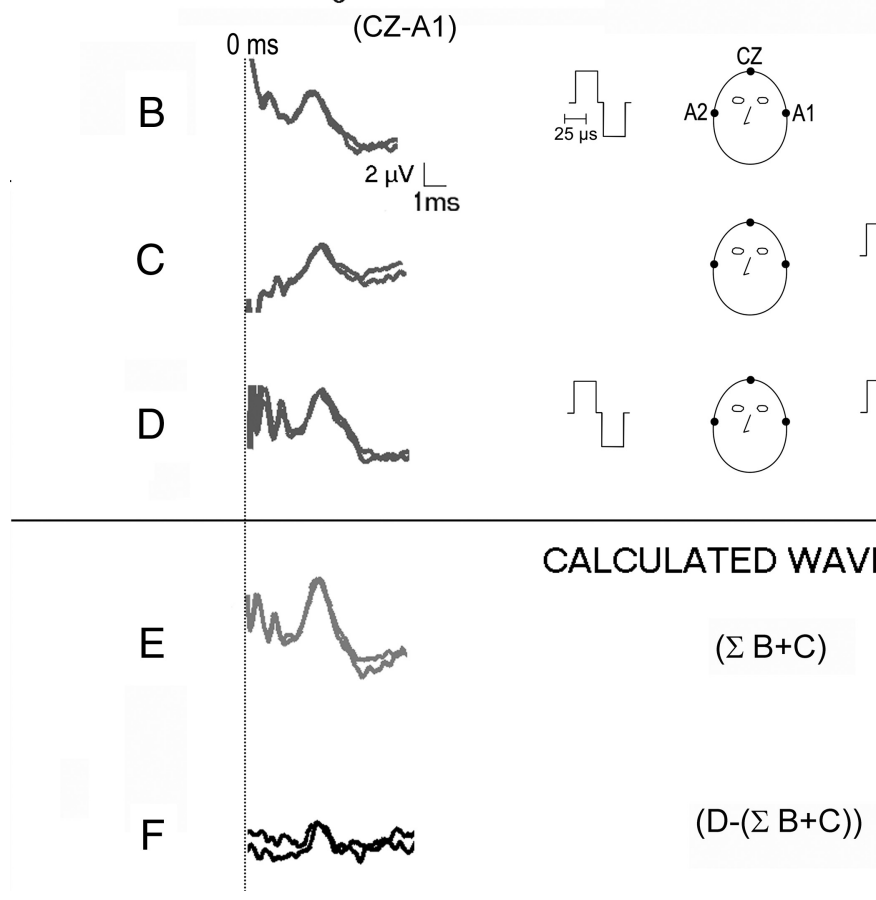

Recording Channel 2

(CZ-A2)

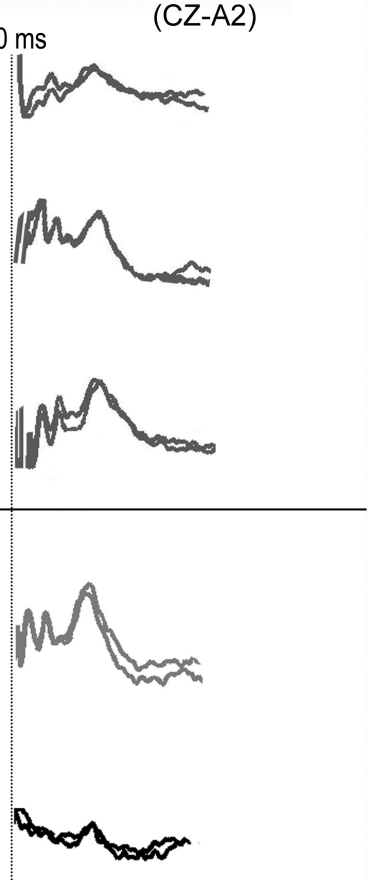

Figure 2. A, The electrically evoked auditory brainstem response is characterized by a large stimulus artifact followed by 3 positive amplitude peaks. These correspond to relays of neural activity along the auditory brainstem and midbrain. $\boldsymbol{B}-\boldsymbol{D}$, Typical EABR waveforms (2 replications each) from two recording channels [CZ (midline cephalic location) referenced to A1 (left earlobe) in Channel 1 and to A2 (right earlobe) in Channel 2] are shown for 3 stimulus conditions: $\mathrm{Cl}$ evoked (B), $\mathrm{Cl} 2$ evoked ( $\boldsymbol{C}$, and binaurally evoked (D). $\boldsymbol{E}, \boldsymbol{F}$, Mathematically generated waveforms are also shown: summed Cl1- and $\mathrm{Cl} 2$-evoked responses $(\boldsymbol{E})$ and the derived BD waveform $(\boldsymbol{F})$.

of stimuli for a particular child was $200-220$ CUs, bilateral presentations would occur at (CU for CI1/CU for CI2) 200/220 (ILD = -20), 205/215 $(\mathrm{ILD}=-10), 210 / 210(\mathrm{ILD}=0), 215 / 205(\mathrm{ILD}=10)$, and 220/200 $(\mathrm{ILD}=20)$ and unilateral stimuli would be presented at 220, 215, 210, 205, and 200 CUs. Bilateral stimuli were delivered from the same stimulating electrodes ( 18 on both CIs). These electrodes were programmed to stimulate in response to the same bandwidth of acoustic frequencies for all of the study participants, thus, the use of the same bilateral CI electrodes was consistent with the children's everyday listening experience.

$\mathrm{BD}$ waveforms were compared with behavioral lateralization responses in 15 children. Stimuli for this task were $500 \mathrm{~ms}$ pulse trains delivered by the apical electrode 18 on both CIs. Stimulus parameters were the same as those used to evoke electrophysiological recordings. Eleven bilateral conditions (ILDs, $\pm 20, \pm 10,0$; and inter-implant timing differences of $\pm 2000, \pm 1000$, and $\pm 400 \mu$ s, where + indicates CI2 lead- ing and - indicates CI1 leading) and two unilateral conditions (CI1 and CI2) were presented in random order. We also asked children to indicate where they heard the bilateral input. In pilot testing, normally hearing children naturally pointed to the middle of their head when bilateral input was matched in intensity between the ears (ILD $=0$ ) whereas children who used bilateral cochlear implants rarely indicated a perception of bilateral input to come from the middle of the head and sometimes indicated that they heard bilateral input as coming from both CIs at the same time (Salloum et al., 2010). Based on this information, we asked children to identify whether they heard the input as coming from the left, right, middle or both sides of their head. Each stimulus condition was presented 6 times randomly within a single block of presentations.

Analyses. Electrophysiological waveforms were visually analyzed by an observer blinded to information regarding the child and stimulus condition. A time window of $2-10 \mathrm{~ms}$ was used for visual inspection of wave- 
forms using MatLab 6.5.2 (MathWorks). Latency was measured at the positive peak and amplitude was defined as the difference from this peak to the following trough. We validated this technique by comparing $\mathrm{BD}$ amplitudes measured in this way to changes in ILD with measure of variability in amplitude in the expected $\mathrm{BD}$ latency range as proposed by $\mathrm{He}$ et al. (2010). As in that paper, we calculated the root mean square measure of variability (square root of the arithmetic mean of the square of difference between the individual voltage measures recorded) during the time window of 3.5-5 ms after stimulus onset (latency) and found a strong correlation between our amplitude measurements and these values $(r=0.59, p<0.0001)$.

Effects of changes in stimulus conditions on $\mathrm{BD}$ and $\mathrm{eV}$ latencies and amplitudes were analyzed using SPSS Version 17.0. We aimed to define a point at which bilaterally presented pulse trains were perceived by each child as "balanced" in terms of intensity. Because children using CIs mainly indicated that they heard bilateral input as coming from the "left" or "right," we defined "balanced levels" as the ILD at which children were equally likely to report sounds as coming from the left as from the right side. Cumulative Gaussian fits were calculated from each child's responses toward CI1. The ILD (dB) corresponding to 0.5 probability indicated "balanced" perceptual responses. This value was used for comparing behavioral and electrophysiological outcomes.

\section{Results}

\section{Binaural interaction is evoked by stimulation from matched CI electrodes}

Activity evoked by bilateral stimulation of electrodes at the same location along the two CI arrays was reduced in amplitude relative to the sum of unilateral input for matched apical electrodes (electrode 20 on both CIs and electrode 18 on both CIs) and for a matched basal electrode (electrode 3 on both CIs). This reduction in response amplitude led to a clear peak in the $\mathrm{BD}$ measure as shown in Figure $2 E$. There was no significant relationship between $\mathrm{BD}$ amplitude (mean $\pm \mathrm{SD}, 0.68 \pm 0.26 \mu \mathrm{V}$ ) and latency $(3.91 \pm 0.20 \mathrm{~ms})(r=-0.06, p>0.05)$.

\section{Binaural interaction of stimulation from matched CI electrodes is present despite unilateral auditory deprivation} We previously showed that a period of unilateral CI use promotes development of the auditory brainstem pathways as measured by decreasing response latencies (Gordon et al., 2003, 2006) but also sets up a mismatch in timing of auditory brainstem activity between the experienced side and the more recently implanted side (Gordon et al., 2007c, 2008). Here we asked whether differences in timing of auditory brainstem activity evoked by each side alter binaural processing with CIs in children. Figure 3 shows a typical series of evoked potential measures from the auditory brainstem in a child receiving bilateral CIs simultaneously (A) and in a child that used a single $\mathrm{CI}$ for a number of years before receiving a second CI (B). The difference in wave $\mathrm{eV}$ latency between the unilaterally evoked responses was clear in the child with sequen-
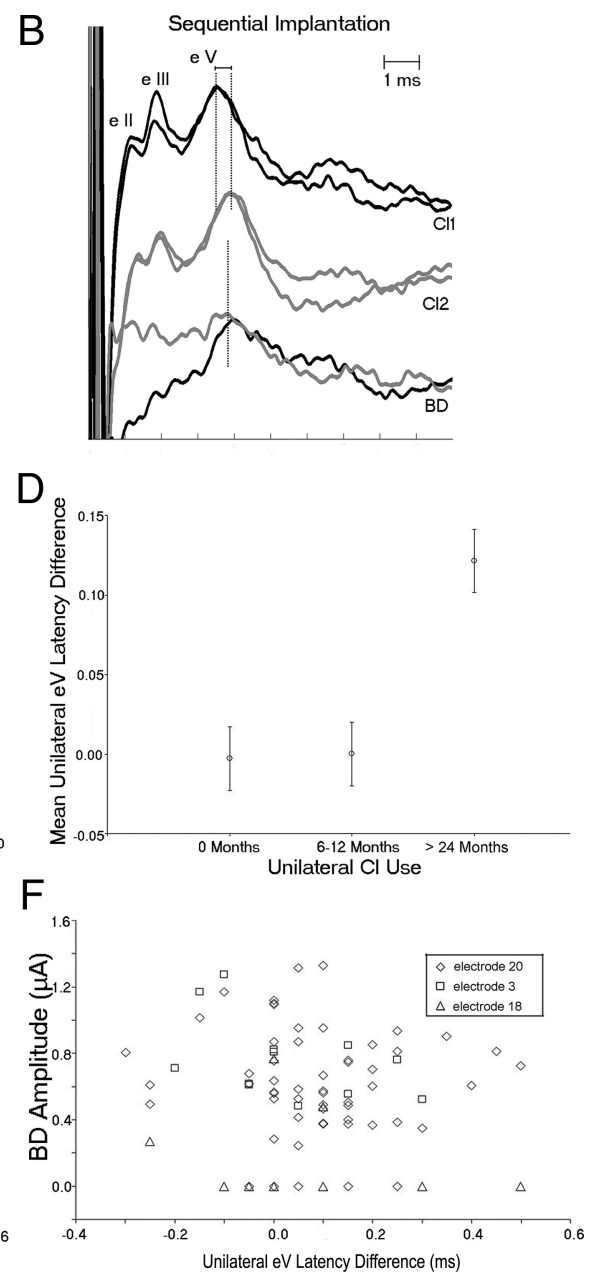

Figure 3. $A$, EABR wave eV evoked by the CI1 (right implant) and CI2 (left implant) are at similar latencies to the BD in a child latency evoked by $\mathrm{Cl} 1$ and the response from $\mathrm{Cl} 2$ remains delayed despite 2 years of bilateral $\mathrm{Cl}$ use. The $\mathrm{BD}$ is delayed relative to the

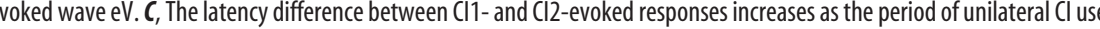
$\boldsymbol{E}$, The $\mathrm{BD}$ becomes more prolonged relative to the faster $\mathrm{eV}$ as the difference in unilateral $\mathrm{eV}$ latencies increases. $\boldsymbol{F}$, The unilateral latencies differences have no significant effect on BD amplitude.

tial bilateral CIs and not in the child using bilateral CIs provided simultaneously. Also, as previously reported (Gordon et al., 2007a), the BD latency was prolonged relative to the $\mathrm{eV}$ on the more experienced side (CI1). Figure $3 C$ indicates that, as expected, the auditory brainstem response latency differences between the first and the newly implanted sides became more disparate as the duration of unilateral CI use increased. The mean differences, shown in 3D, were significantly greater in the group with $>2$ years of unilateral CI use compared with children receiving bilateral CIs simultaneously or with more limited periods of unilateral CI use $\left(F_{(2)}=8.07 ; p<0.01\right)$. Figure $3 E$ indicates that, relative to the faster $\mathrm{eV}$ (typically evoked by $\mathrm{CI} 1$ in children with long periods of unilateral CI use), the BD peak latency increased as the difference in unilaterally evoked wave $\mathrm{eV}$ latencies increased $(r=0.65, p<0.01)$. This was also consistent with previous reports (Gordon et al., 2007a). There was no similar effect of mismatched wave $\mathrm{eV}$ peak latencies on $\mathrm{BD}$ amplitude as shown in Figure $3 F$. Because the children in the simultaneous group were younger than those in the sequential group, we assessed the effect of age on these responses. Age at CI1 did not significantly predict either unilaterally evoked $\mathrm{eV}$ latency differences $(r=0.16$; 
A

Matched Place
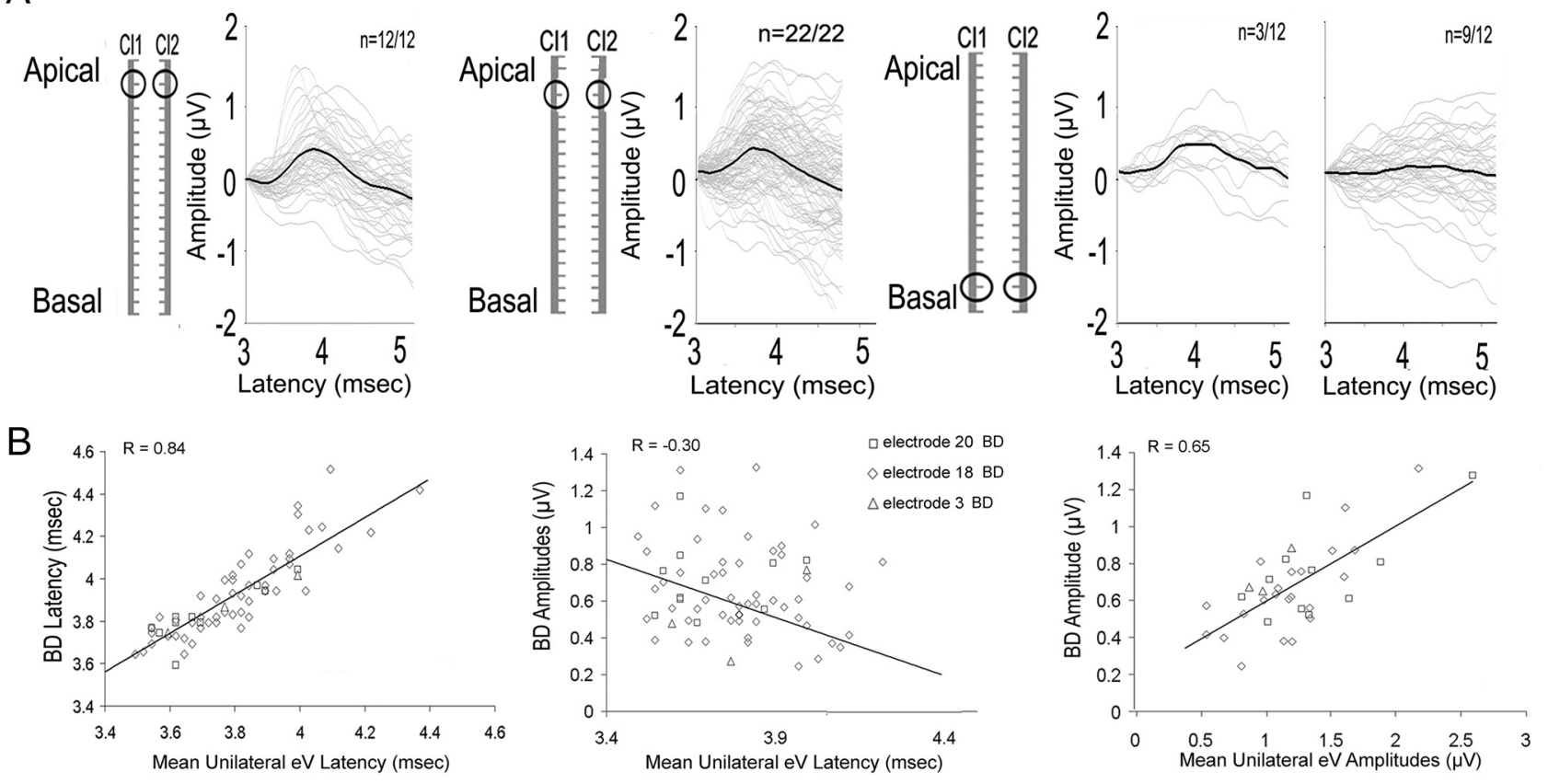

\section{Large Mismatch in Place}
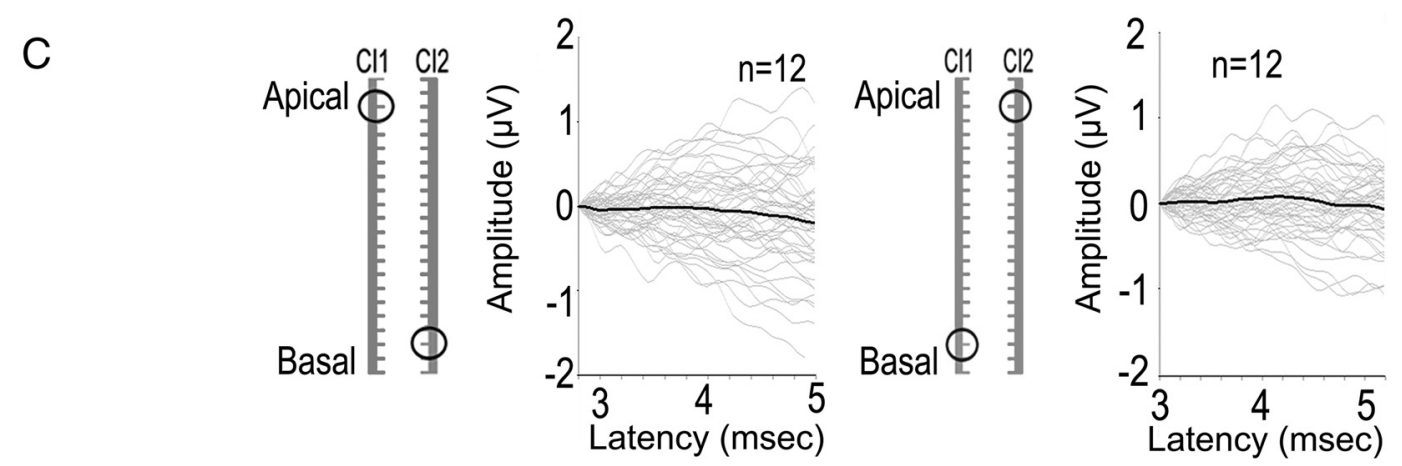

D
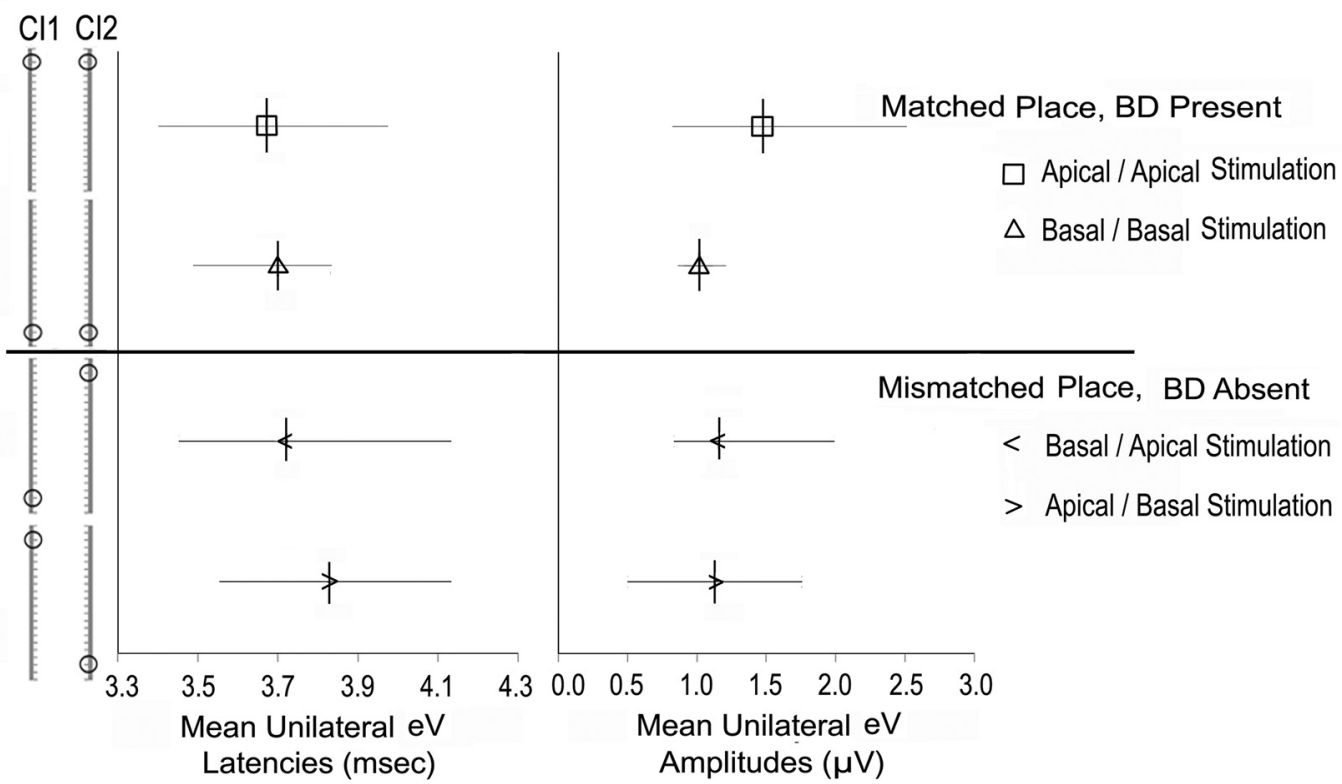

Figure 4. A, Data from individual children, shown by thin gray lines, and mean data, indicated by the thick black lines, show that the BD was evoked by stimulation matched either at the apical (\#20 and \#18) or basal ends (\#3) of the implanted array (BD was present more often in response to matched apical than matched basal stimulation). B, The latency of the BD to matched electrode stimulation was strongly tied to the mean latency of unilaterally evoked responses. BD amplitudes decreased as the mean unilaterally evoked wave eV latency increased, and (Figure legend continues.) 
$p>0.05)$ or the $\mathrm{BD}$ latency delay relative to $\mathrm{CI} 1$-evoked $\mathrm{eV}$ latency $(\mathrm{BD}-\mathrm{CI} 1 \mathrm{eV})(r=-0.01 ; p>0.05)$. Age at CI2 was not assessed because it was strongly related to the period of unilateral CI use $(r=0.92 ; p<0.01)$.

\section{Binaural interaction is eliminated by large mismatches in} place of electrical stimulation between two cochlear implants Having shown that binaural inhibition can be evoked in children using bilateral CIs, we tested whether this process was affected by place of stimulation. This would be expected in the normal auditory pathways due to tonotopic arrangement (Smith and Delgutte, 2007a). Our first step was to determine whether we could completely disrupt binaural processing by providing an exaggerated mismatch between the place of stimulation on the left and right sides. To this end, bilateral stimulation was provided from opposite locations of the electrode array; stimulus from one CI was provided at the apical end of the array while stimulus from the other CI was delivered by an electrode at the basal end in 12 children. BD responses to matched and unmatched places of bilateral stimulation are shown in Figure 4.

The top panel in Figure $4 A$ shows responses that were evoked by matched places of stimulation. These responses show that 12 of 12 children had clear BD responses to matched apical (electrode 20) stimulation, 22 of 22 children had clear responses to matched electrode \#18 stimulation and 3 of 12 (participants 24, 53 , and 55) had clear BD responses to matched basal (electrode 3 ) electrode stimulation. Figure $4 B$ demonstrates the effects of unilateral response latencies and amplitudes on the $\mathrm{BD}$ response to matched electrodes. The most important predictor of BD latency in the matched condition was found to be the mean latency of unilaterally evoked wave eVs; as shown in the left plot of $4 \mathrm{~B}$, these variables had a strong $(r=0.84, p<0.01)$ and almost direct (slope $\pm \mathrm{SE}=0.91 \pm 0.59)$ positive relationship. The BD latency was also significantly related to $\mathrm{eV}$ latency evoked by CI1 and by CI2 individually ( $r=0.75$ and 0.81 , respectively). The middle plot of $4 \mathrm{~B}$ shows a significant relationship $(r=-0.30, p<0.05)$ between the latency of the unilaterally evoked wave eVs and that of the BD amplitude but in the negative direction. Thus, faster (typically more developed and more synchronous) activity in the auditory brainstem of deaf children predicted larger magnitudes of binaural inhibition at similar latencies. As shown in the right plot of $4 \mathrm{~B}$, smaller amplitude EABRs also strongly predicted smaller amplitudes of binaural interaction $(r=0.65, p<0.01)$.

In contrast to the clear $\mathrm{BD}$ responses to matched electrode stimulation, large mismatches in place of stimulation between the two CIs completely disrupted binaural interaction in the auditory brainstem in the same children as measured by an absence of observable $\mathrm{BD}$ responses in all 12 cases. These responses are shown in Figure 4C. Because mean latencies and amplitudes of unilaterally evoked brainstem responses affect the BD latency and amplitude, we assessed whether there were any differences in mean latencies provided by the mismatched electrodes which could explain the absence of BD responses. Figure $4 D$ highlights differences in the mean latencies between matched and largely mismatched electrodes $\left(t_{(37)}=-2.47, p=0.02\right)$ but shows that

$\leftarrow$

(Figure legend continued.) increased as the mean unilaterally evoked amplitudes (of wave eV) increased. C, Large mismatches in place of stimulation eliminated the BD. D, Mean (dashes) and $95 \%$ confidence intervals of latencies and amplitudes of the two unilaterally evoked wave eVs are shown for both matched and mismatched place of bilateral Cl stimulation. No significant amplitude differences were found indicating that absent BDs with large mismatches in place of bilateral stimulation cannot be explained by differences in evoked brainstem activity. mean amplitudes of responses evoked unilaterally by CI1 and by CI2 were not significantly different $\left(t_{(37)}=1.81, p=0.08\right)$. Thus, differences in unilaterally evoked brainstem activity could not explain the absence of BDs in response to large mismatches in place of stimulation.

\section{Binaural interaction is not affected by small mismatches in} place of electrical stimulation between two cochlear implants Given the elimination of binaural interaction with large mismatches in place of stimulation between the two CIs, we asked whether smaller place mismatches (more typical of a clinical situation) would affect the response to bilateral stimulation. To do this, we held the stimulating electrode on one CI constant (at electrode 18) and varied the position of the stimulating electrode on the other CI by up to 4 electrode locations in both the apical and basal directions $(14,16,18,20$, or 22$)$. Figure $5 A$ shows the place of stimulation (electrode 18 shown by a filled circle) for all 9 conditions and the resultant BD waveforms, when present, for all 29 children who participated in this part of the study (thin gray lines) along with the mean BD for each condition (thick black line).

Measurable BDs were observed at all electrode pairs in 18 of 29 of the participants. Figure $5 B$ shows $\mathrm{BD}$ amplitudes and latencies (top left and bottom left panels, respectively) when CI2 was held at electrode 18 and CI1 electrode moved from 14 to 22 . Figure $5 B$ shows amplitudes and latencies (right top and right bottom panels, respectively) when CI1 was held at electrode 18 and CI2 electrode moved from 14 to 22. No significant changes in BD amplitude $\left(F_{(8,11)}=0.27, p>0.05\right)$ were found between the 9 conditions indicating no observable effect of small mismatches in place of apical stimulation between the two CIs on the magnitude of binaural inhibition. Similarly, BD latencies did not change significantly with varied electrode numbers $\left(F_{(8,11)}=1.59, p>\right.$ $0.05)$. There was no significant effect of fixed side for amplitude $\left(F_{(1,111)}=0.65, p>0.05\right)$ or latency $\left(F_{(1,111)}=2.09, p>0.05\right)$.

\section{The binaural difference amplitude is largest when bilateral activity is balanced in level}

One of the two dominant binaural cues used for locating a sound in space is the ILD. Level cues are first processed in the lateral superior olive of the auditory brainstem. We asked whether binaural processing in the auditory brainstem of deaf children changes in response to ILDs delivered by bilateral CIs. To take into account differences in current conversion between different generations of $\mathrm{CI}$ devices, $\mathrm{CU}$ values were converted to decibels. This meant that ILDs measured in $\mathrm{dB}$ ranged from -4 to $3.5 \mathrm{~dB}$ (where - indicates level weighted to CI1 and + indicates level weighted to CI2) and were not the same for all children. As shown in Figure $6 \mathrm{~A}$, unilaterally evoked $\mathrm{eV}$ amplitudes increased with stimulus intensity. The $\mathrm{eV}$ amplitudes evoked by the second implanted side (mean $\pm \mathrm{SD}, 1.08 \pm 0.48 \mu \mathrm{V}$ ) were greater than those evoked by the first (mean $\pm \mathrm{SD}, 0.83 \pm 0.38 \mu \mathrm{V}\left(t_{(174)}=\right.$ $-5.73, p<0.01)$ across stimulus intensities, confirming previously reported data from our group (Salloum et al., 2010). Further analyses indicated that the 18 children who used newer generations of CIs (N24RE) in the second implanted ear compared with the first (N24M, CS or CA) had larger eV amplitude differences between sides $(0.37 \pm 0.52 \mu \mathrm{A})$ versus those with more similar devices bilaterally $(0.13 \pm 0.62 \mu \mathrm{A})\left(t_{(173)}=2.73\right.$, $p<0.05)$. Unilaterally evoked wave $\mathrm{eV}$ latencies, shown in Figure $6 \mathrm{~B}$ did not change significantly with increased stimulus intensity $\left(\mathrm{CI} 1: F_{(5,170)}=0.36, p>0.05\right.$ and CI2: $\left.F_{(5,170)}=0.28, p>0.05\right)$ which is consistent with previous findings that EABR latency is 
A $\quad \mathrm{Cl} 2$ Fixed at Electrode 18, Cl1 Electrode Moved
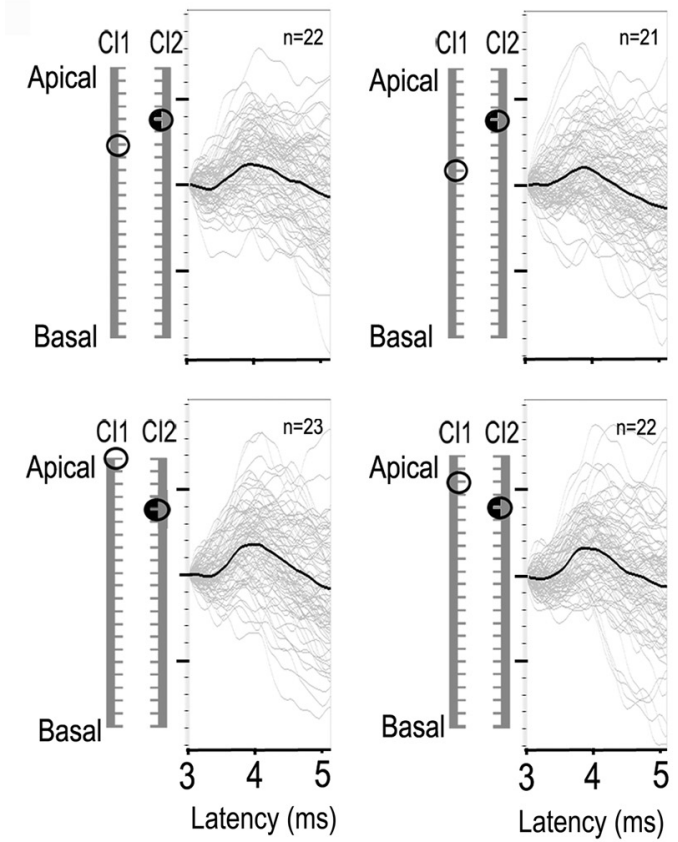

B
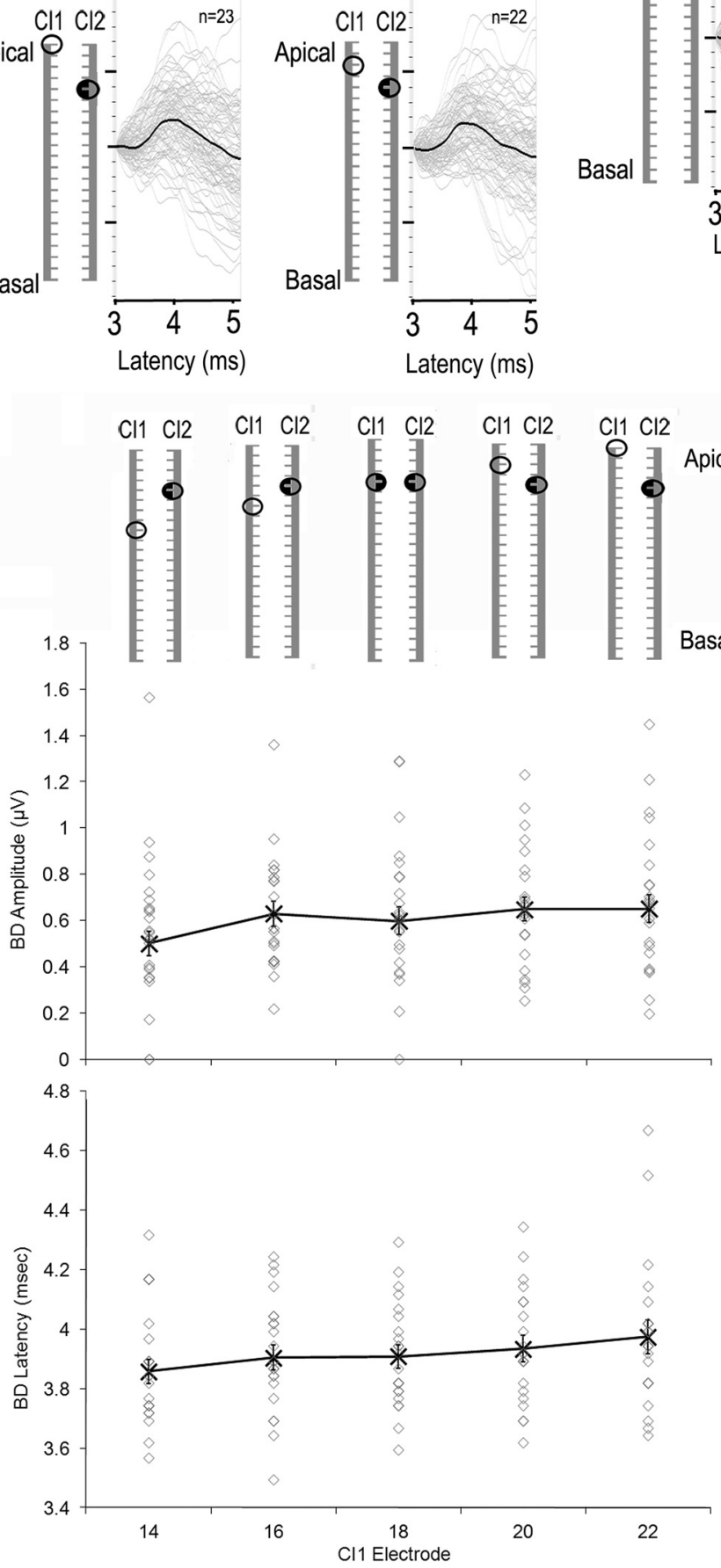

Cl1 Fixed at Electrode 18, Cl2 Electrode Moved
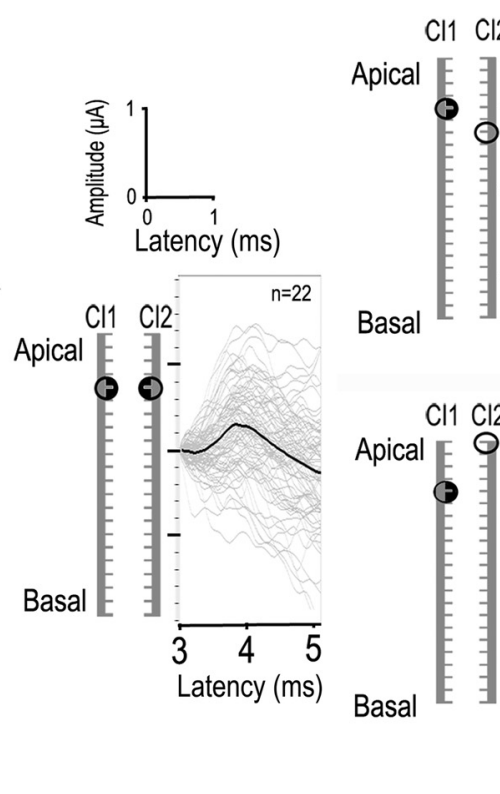
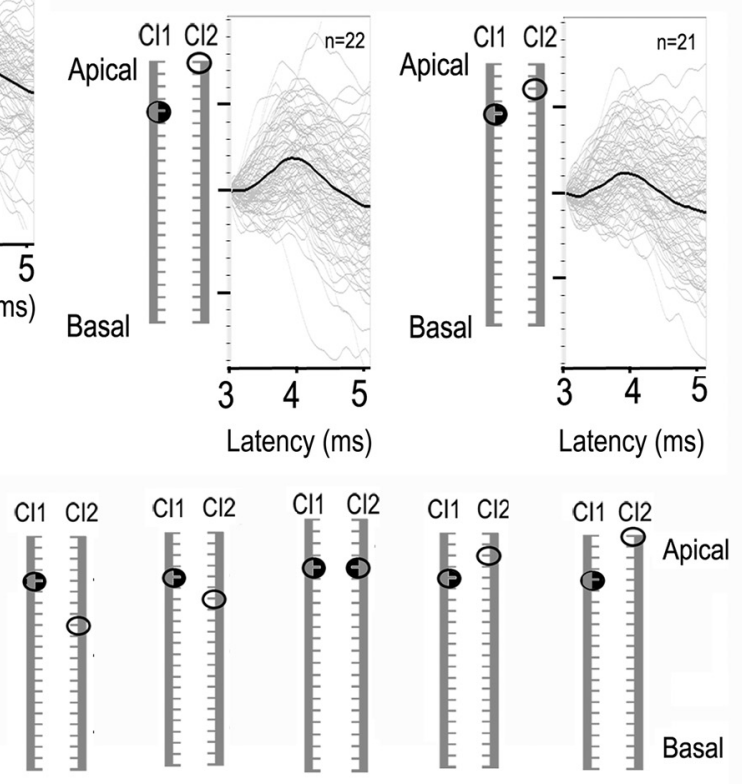

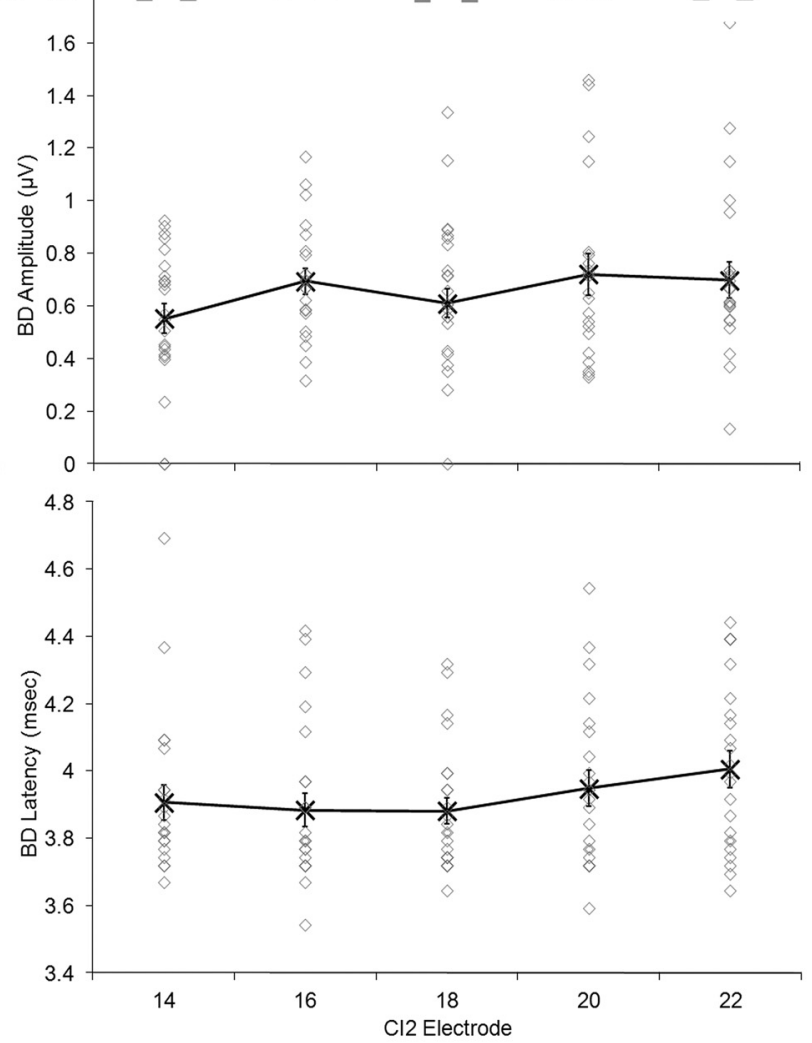

Figure 5. BDs were measured in response to small place mismatches in bilateral Cl stimulation in 29 children. Stimulation was delivered from electrode 18 on one Cl and was moved on the other Cl from electrode 14 to the more apical electrode 22. Data for conditions in which CI2 electrode was fixed at 18 are shown on the left and conditions in which CI2 electrode (Figure legend continues.) 

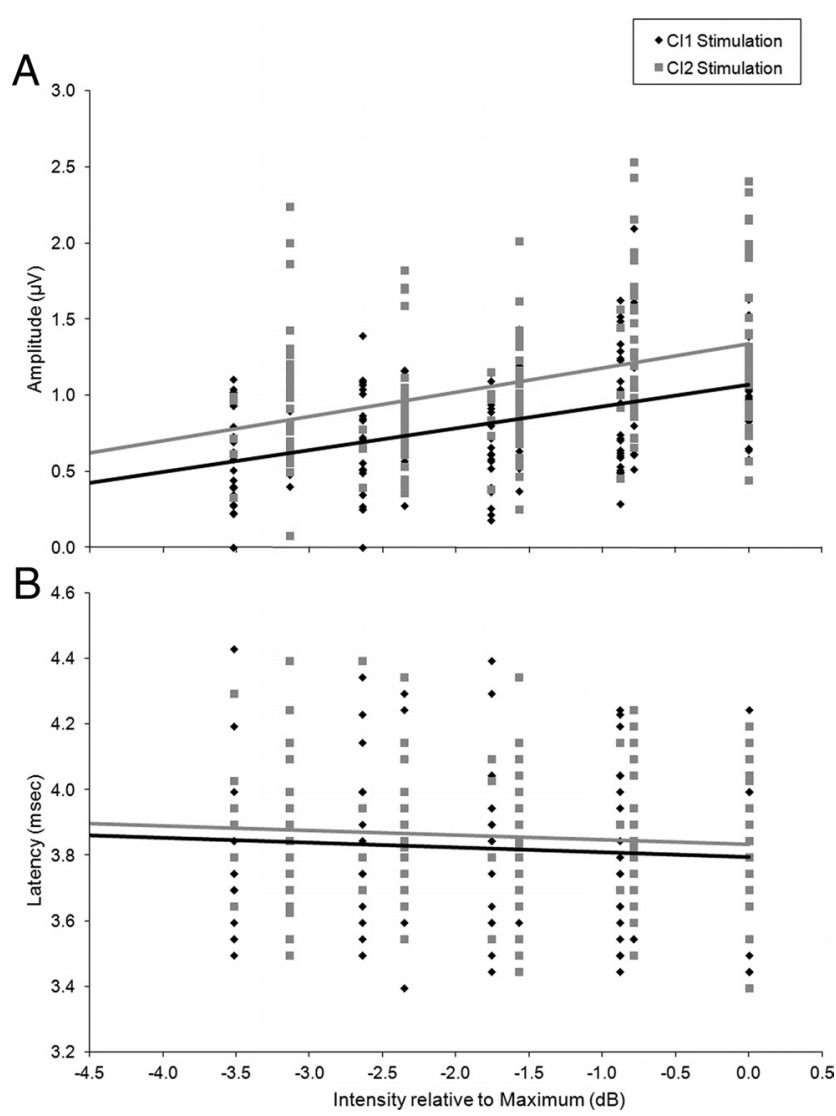

Figure 6. Unilaterally evoked EABRs were recorded at a fairly loud range of current intensities: $\boldsymbol{A}$, amplitudes increased with increasing intensity levels; and $\boldsymbol{B}$, latencies did not change significantly.

fairly stable at a range of loud input intensities (Gordon et al., 2003).

Binaural interaction was measured for all ILD conditions. The ILD conditions are shown in Figure 7A. The corresponding mean BD amplitudes and latencies are shown in Figure 7, $B$ and $C$, respectively, with ILD measured in $\mathrm{dB}$. Mean $\mathrm{BD}$ amplitudes increased as ILDs became less weighted to CI2 $\left(F_{(5,156)}=5.35\right.$, $p<0.01)$ but BD latency did not change significantly $\left(F_{(5,147)}=\right.$ $1.88, p>0.05)$.

\section{Amplitude of binaural difference predicts behavioral perception}

Fifteen children completed a behavioral task in which they were asked to indicate whether they heard bilateral pulse presentations as coming from the left, right, middle of their head or from both sides simultaneously. Studies of children with normal hearing indicate that bilateral clicks with ILDs weighted to the left or right are perceived as coming from the left or right sides, respectively, and bilateral input with balanced intensities are perceived as

(Figure legend continued.) remained at 18 are shown on the right. $\boldsymbol{A}$, The BDs which were present are shown for each condition; the thin gray lines represent individual responses and thick black lines represent the mean. Eighteen of the 29 children showed clear BDs in all conditions and BDs were found in at least 21 of the children in each condition. $B, B D$ amplitudes and latencies are plotted for each condition. Individual data are shown by the gray open circles. Mean values are indicated by black X symbols and joined by the black line. No significant changes in either BD latency or amplitude were found as the place of stimulation varied in the apical end regardless of which Cl was fixed at electrode 18.

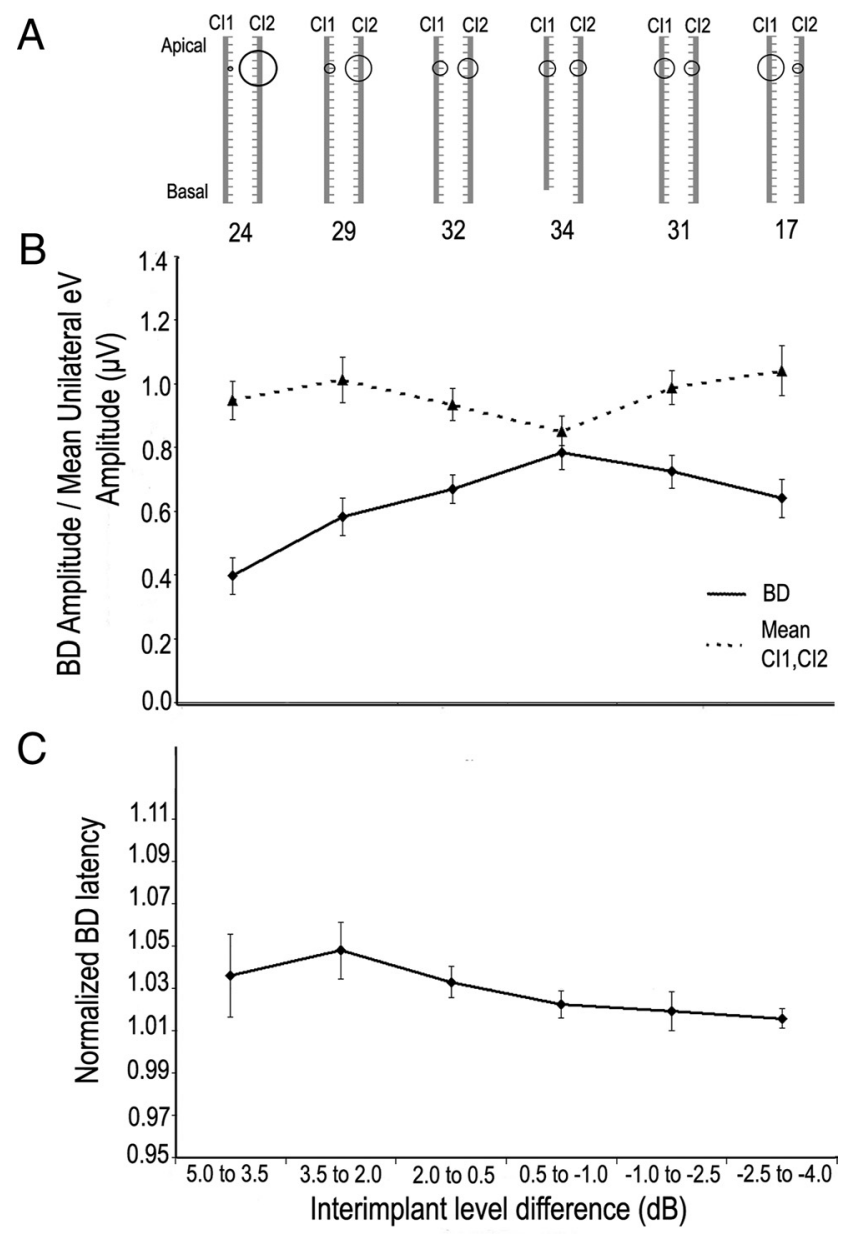

Figure 7. $\quad A$, Intensity differences between the two apical electrodes were varied while keeping the total current (in CUs) presented constant. B, BDs were recorded in response to all inter-implant level difference conditions, the numbers of recordings are indicated for each condition. Mean BD amplitudes (normalized relative to mean Cl1- and Cl2-evoked eV amplitudes) increase as intensity differences between the two $\mathrm{Cls}$ decreases $\left(F_{(5,156)}=5.35, p<\right.$ 0.01 ). There is no similar change in the mean wave $\mathrm{eV}$ amplitudes. $C$, Mean BD latencies (normalized relative to (I2-evoked eV latency) do not significantly change with changing interimplant level differences $\left(F_{(5,147)}=1.88, p>0.05\right)$.

coming from the middle of the head (Salloum et al., 2010). Children using bilateral CIs sometimes indicated that they heard bilateral input as coming from both sides at once but rarely indicated "middle" in response to any of the bilateral stimuli; thus, the percentages of right and left responses were analyzed. Figure $8 \mathrm{~A}$ shows behavioral responses from a representative participant (Participant 23). Her responses indicate that ILDs of 4.2-0.9 $\mathrm{dB}$ were perceived as coming from the side of the head ipsilateral to CI2 and ILDs -0.8 to $-2.5 \mathrm{~dB}$ produced lateralization toward the side ipsilateral to CI1. Gaussian regression curves were fit to each child's lateralization responses (number of CI1/ CI1 + CI2 responses) using a bootstrap procedure. The ILD corresponding to lateralization responses which were away and toward CI1 with equal probability $(0.50)$ was used to indicate balance (i.e., the ILD at which there was no lateralization). The Gaussian fit calculated from Participant 23's responses is represented in Figure $8 B$; the 0.50 response probability occurred at $0.58 \mathrm{~dB}$ ILD as highlighted by dashed lines. BD amplitudes recorded in the same child for all ILD conditions are shown in Figure $8 C$ illustrating an increase in $\mathrm{BD}$ amplitude as weighting of bilateral stimulation to $\mathrm{CI} 1$ or $\mathrm{CI} 2$ decreased. 


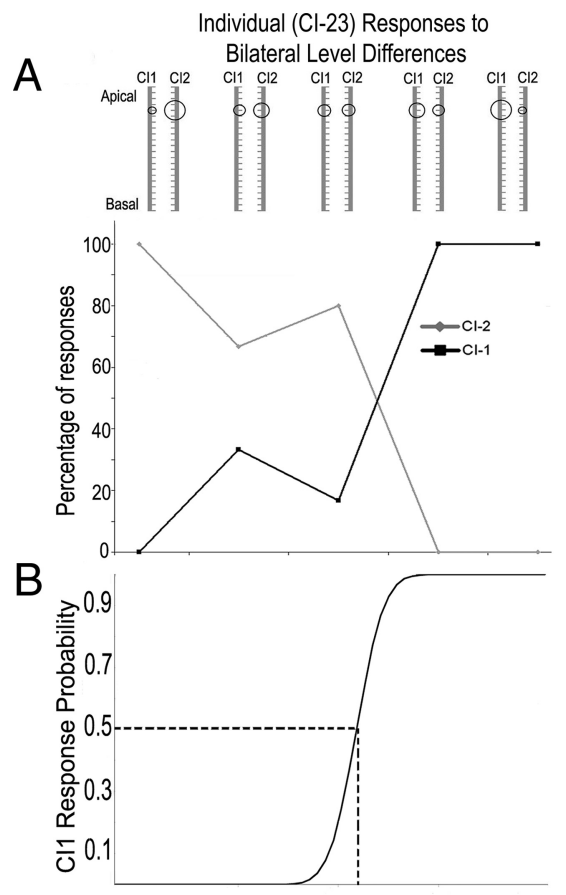

C
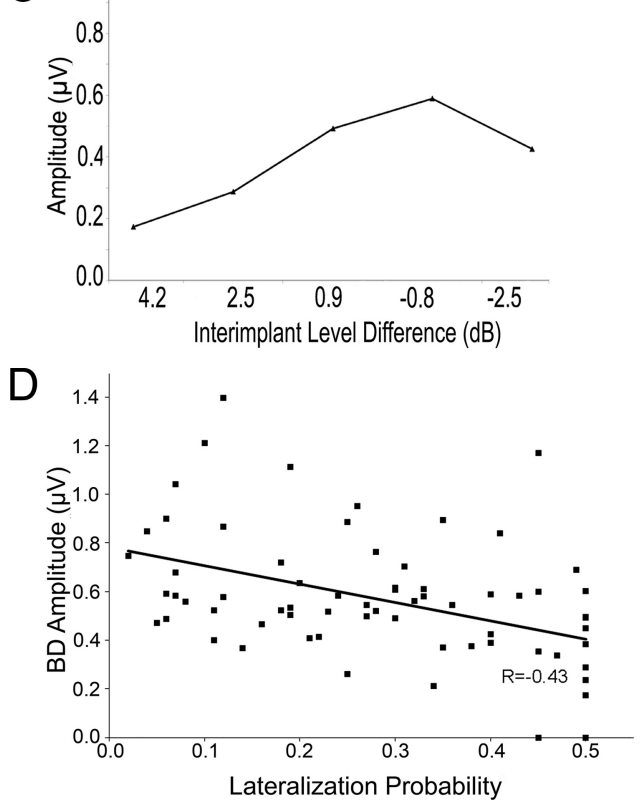

Figure 8. A, Participant 23 indicated whether she heard bilaterally presented stimuli as louder or coming from the $\mathrm{C} 11$ side or the $\mathrm{Cl} 2$ side. The levels provided to each $\mathrm{Cl}$ are shown schematically. The percentage of responses to $\mathrm{Cl} 2$ decreased as intensity of $\mathrm{Cl} 2$ decreased and percentage of responses to $\mathrm{Cl} 1$ increased as intensity of $\mathrm{Cl} 1$ increased. $\boldsymbol{B}$, Gaussian regression on $\mathrm{Cl} 1$ responses identified a point at which there were no greater $\mathrm{Cl} 1$ than $\mathrm{Cl} 2$ responses $(0.5$ probability of $\mathrm{Cl} 1$ response). $\mathrm{C}$, BDs were measured in response to the same stimuli. Amplitudes increased until there was a $0.8 \mathrm{~dB}$ weighting of levels in $\mathrm{Cl} 1$ compared with $\mathrm{Cl} 2$ levels with a decrease in BD amplitude as levels became further weighted to $C$ I1. $D, B D$ amplitude decreases as behavioral responses shift away from mid-line $(r=-0.43 ; p<0.01)$.

Figure $8 D$ compares behavioral responses to bilateral input to $\mathrm{BD}$ amplitudes evoked by the same stimuli. Behavioral responses were measured as the probability of lateralization away from mid-line. This was done using the lateralization probability at each ILD defined by the Gaussian curve (as in the example in Fig. $8 B$ ) subtracted by 0.5 (which defined the mid-point). The data are presented as absolute values, with values closer to zero repre- senting localization to the midline and larger values being away from midline. As shown in the figure, BD amplitudes decreased as behavioral responses shifted further from mid-line $(r=-0.43$, $p<0.01)$.

\section{Discussion}

The present study shows that the developing human auditory system can integrate information presented through bilateral CIs as measured by an amplitude decrease between the measured response to bilateral input and the sum of the two unilateral responses. In normal hearing individuals, this binaural difference (BD) measure is thought to reflect inhibitory modulation of bilateral input (Dobie and Berlin, 1979; Ainslie and Boston, 1980; Dobie and Norton, 1980; Dobie and Wilson, 1985; Brantberg et al., 1999). The BD has been reported in bilateral CI users who became deaf in adulthood (humans: He et al., 2010; cats: Smith and Delgutte, 2007a,b), indicating that bilateral electrical stimulation can be integrated in pathways which had presumably developed normal binaural function before the onset of deafness. The immature auditory system, by comparison, is subject to abnormal development and reorganization if left deprived of sufficient input (Lee et al., 2001).

A unilateral CI can protect the brain from deprivationinduced reorganization and drive reductions in auditory brainstem response latencies (Gordon et al., 2006), reflecting increased velocity of axonal conduction and/or synaptic relays (Eggermont, 1995). However, these positive changes also establish timing differences in brainstem activity when evoked by stimulation in the experienced versus newly implanted ear (Gordon et al., 2008) which might compromise binaural processing. In addition, unilateral stimulation causes reorganization along the brainstem pathways which disrupts binaural processing (Popescu and Polley, 2010). It was therefore remarkable to find that $\mathrm{BD}$ amplitudes did not significantly change as the asymmetries in latencies of CI1- and CI2-evoked responses increased (Fig. 3F). These latency differences were associated with prolonged $\mathrm{BDs}$ relative to the more symmetrical responses (Fig. 3E) which is consistent with previous findings (Gordon et al., 2008). Further analyses revealed that the strongest predictor of BD latency was the mean latency of the unilaterally evoked responses (Fig. 3A); this was an almost direct relationship (slope $\pm \mathrm{SE}=0.91 \pm 0.59$ ) suggesting that binaural processing does not alter timing of neural conduction through the bilateral auditory brainstem pathways. In addition, the BD amplitude increased when brainstem activity occurred at shorter latencies and with larger amplitudes (Fig. $4 B$ ). Instances of shorter latencies and larger amplitudes in far field responses typically reflect increases in synchronous activity (Eggermont, 1995), which, in this case, indicates that the efficiency of binaural processing depends upon the state of the brainstem pathways.

The dependence of the BD on the strength and development of the brainstem pathways was further demonstrated by the finding that binaural interaction was clearer when evoked by apical than basal CI electrodes (Fig. 4). The binaural difference response was evoked in all children with apical electrode stimulation compared with only 3 of 12 children with basal stimulation. This is in line with evidence that auditory nerve and brainstem activity is of higher amplitude when evoked by apical than basal CI electrodes (Propst et al., 2006; Gordon et al., 2007b).

A complete elimination of binaural processing, as indicated by the absence of BDs, was found when stimulation was provided from opposing ends of the two arrays (Fig. 4C). This outcome cannot be due to insufficient stimulation in the auditory brainstem; although mean latencies of left and right evoked responses 
were slightly longer for mismatched than matched stimulation, amplitudes were not significantly different (Fig. 4D). The lack of binaural interaction with large mismatches in place of bilateral stimulation is further evidence that: a) children who are deaf retain some degree of tonotopic pathway organization and b) the interaction of bilateral electrical input is dependent upon this organization. These findings fit with the idea that there is coincident processing of bilateral stimulation when input from the right and left ears converge on specific SOC neurons (Moore, 2000).

It is not surprising that binaural processes were dependent on the tonotopic organization of the auditory pathways. In deaf animal models, BD amplitude was largest when place of stimulation was matched and this corresponded with the largest overlap in areas of activity in the inferior colliculi of the auditory midbrain (Smith and Delgutte, 2007a). Moreover, in adults using bilateral CIs, mismatches in place of stimulation of 3-5 mm compromised sensitivity to inter-implant timing differences (Long et al., 2003; van Hoesel, 2004; Poon et al., 2009). Such changes could occur due to slight differences in position between the two electrode arrays or electrodes. If so, there might be more optimal electrode pairings than those assumed by treating the two arrays as equal with respect to place of stimulation. With this in mind, we asked whether smaller mismatches in place of stimulation would disrupt binaural processing in children using bilateral CIs.

As shown in Figure 5, moving electrode position in one CI relative to the other within the apical end had little effect on the $\mathrm{BD}$ amplitude or latency. This was also reported in adult CI users (He et al., 2010). The results likely reflect a large spread of current from each CI electrode particularly at the levels provided in the present study. This can be reduced slightly by delivering lower stimulation levels (He et al., 2010). With higher rates of electrical pulse presentation, spread of current from individual CI electrodes can extend as wide as $5.86-10.95 \%$ of the length of the Organ of Corti (Cohen et al., 2003) or 5.0-7.4 electrode positions (Hughes and Abbas, 2006). On one hand, this reduces the number of independent frequency channels represented by the CI, compromising pitch and music perception in CI users. On the other hand, this means that small mismatches in places of stimulation between the two CIs are unlikely to significantly distort binaural processing in children.

Figure $6 \mathrm{~A}$ shows that amplitudes of unilaterally evoked brainstem responses were slightly larger when evoked by CI 2 than CI1 at all intensities of current presented. Because the growth of amplitude was not significantly different between the two sides, the increase in amplitude evoked by CI2 is likely due to an upgrade in the device, specifically the use of a Nucleus Freedom (N24RE), rather than differences in brainstem function. For 18 of the 30 children implanted sequentially, CI2 was a newer generation (N24RE) device than that placed in the first ear (N24M, CS or $\mathrm{CA}$ ). The use of precurved electrodes designed to lie closer to the spiral ganglion in the modiolus of the cochlea and the use of half-banded electrodes in newer devices could account for the increased amplitude in brainstem response evoked by CI2. Matching activity between the left and right CIs thus meant providing slightly higher current levels to CI1 than CI2. Indeed, this slight weighting of intensity to CI1 resulted in the largest amplitude BD responses (Fig. $7 B$ ), and is consistent with previous reports (Salloum et al., 2010). Although the mean amplitude of brainstem activity did not change as inter-implant level differences increased, the BD amplitude decreased as levels became more heavily weighted to CI2. This effect was significant for ILDs weighted to CI2, but not to CI1. This can be understood by con- sidering the level imbalance in many of these children favoring $\mathrm{CI} 2$ at matched levels. There was little change in BD latency, which reflects the limited change in $\mathrm{eV}$ latency within the range of intensities provided in this study (Fig. 7C). The BD amplitude changes are consistent with results of Smith and Delgutte (2007a) who found that BD amplitude was greatest in deaf cats when intensities between bilateral CIs were matched.

Data presented in Figure 8 show that the largest BD amplitudes occur when children do not perceive the sound to be lateralized. A proposed mechanism for these observed phenomena could be that, at balanced levels, there is maximum activity in inhibitory circuits converging on the SOC. Observed changes in binaural inhibition may provide cues to higher order centers of the auditory pathways and contribute to changes in perception of bilateral input based on level. Given the difficulty that children using bilateral CIs had in hearing the bilateral input as coming from mid-line, the brainstem responses and $\mathrm{BD}$ may be very useful tools to set balanced levels for their two CIs. This will be particularly important for children receiving different CI devices in each ear.

In summary, the presence of bilateral inhibition in children using bilateral CIs suggests that the auditory brainstem retains the ability to integrate information from each ear despite bilateral and sometimes unilateral auditory deprivation during development. The processing of bilateral input is tonotopically organized to some degree but this may be underutilized for bilateral CI users perhaps because of current spread between electrode sites on each side. Electrically evoked binaural processing in the auditory brainstem codes changes in level cues between the two sides and this is perceived by children using bilateral CIs as a shift in loudness from one side to the other. The children's ability to use level cues suggests that some attention should be paid to the range of level cues provided to each of their CIs to enhance functional use.

\section{References}

Ainslie PJ, Boston JR (1980) Comparison of brain stem auditory evoked potentials for monaural and binaural stimuli. Electroencephalogr Clin Neurophysiol 49:291-302.

Akeroyd MA (2006) The psychoacoustics of binaural hearing. Int J Audiol 45 [Suppl 1]:S25-S33.

Brantberg K, Fransson PA, Hansson H, Rosenhall U (1999) Measures of the binaural interaction component in human auditory brainstem response using objective detection criteria. Scand Audiol 28:15-26.

Cohen LT, Richardson LM, Saunders E, Cowan RS (2003) Spatial spread of neural excitation in cochlear implant recipients: comparison of improved ECAP method and psychophysical forward masking. Hear Res 179:72-87.

Dobie RA, Berlin CI (1979) Binaural interaction in brainstem-evoked responses. Arch Otolaryngol 105:391-398.

Dobie RA, Norton SJ (1980) Binaural interaction in human auditory evoked potentials. Electroencephalogr Clin Neurophysiol 49:303-313.

Dobie RA, Wilson MJ (1985) Binaural interaction in auditory brain-stem responses: effects of masking. Electroencephalogr Clin Neurophysiol 62:56-64.

Eggermont JJ (1995) Evoked potentials as indicators of auditory development. Int J Pediatr Otorhinolaryngol 32:S183-S186.

Furst M, Eyal S, Korczyn AD (1990) Prediction of binaural click lateralization by brainstem auditory evoked potentials. Hear Res 49:347-359.

Goksoy C, Demirtas S, Yagcioglu S, Ungan P (2005) Interaural delaydependent changes in the binaural interaction component of the guinea pig brainstem responses. Brain Res 1054:183-191.

Gordon KA, Papsin BC, Harrison RV (2003) Activity-dependent developmental plasticity of the auditory brain stem in children who use cochlear implants. Ear Hear 24:485-500.

Gordon KA, Papsin BC, Harrison RV (2005) Effects of cochlear implant use on the electrically evoked middle latency response in children. Hear Res 204:78-89. 
Gordon KA, Papsin BC, Harrison RV (2006) An evoked potential study of the developmental time course of the auditory nerve and brainstem in children using cochlear implants. Audiol Neurootol 11:7-23.

Gordon KA, Valero J, Papsin BC (2007a) Binaural processing in children using bilateral cochlear implants. Neuroreport 18:613-617.

Gordon KA, Papsin BC, Harrison RV (2007b) Auditory brainstem activity and development evoked by apical versus basal cochlear implant electrode stimulation in children. Clin Neurophysiol 118:1671-1684.

Gordon KA, Valero J, Papsin BC (2007c) Auditory brainstem activity in children with 9-30 months of bilateral cochlear implant use. Hear Res 233:97-107.

Gordon KA, Valero J, van Hoesel R, Papsin BC (2008) Abnormal timing delays in auditory brainstem responses evoked by bilateral cochlear implant use in children. Otol Neurotol 29:193-198.

Hawley ML, Litovsky RY, Culling JF (2004) The benefit of binaural hearing in a cocktail party: effect of location and type of interferer. J Acoust Soc Am 115:833-843.

He S, Brown CJ, Abbas PJ (2010) Effects of stimulation level and electrode pairing on the binaural interaction component of the electrically evoked auditory brain stem response. Ear Hear 31:457-470.

Hubel DH, Wiesel TN (1970) The period of susceptibility to the physiological effects of unilateral eye closure in kittens. J Physiol 206:419-436.

Hughes ML, Abbas PJ (2006) Electrophysiologic channel interaction, electrode pitch ranking, and behavioral threshold in straight versus perimodiolar cochlear implant electrode arrays. J Acoust Soc Am 119: $1538-1547$.

Jiang ZD, Tierney TS (1996) Binaural interaction in human neonatal auditory brainstem. Pediatr Res 39:708-714.

Lee DS, Lee JS, Oh SH, Kim SK, Kim JW, Chung JK, Lee MC, Kim CS (2001) Cross-modal plasticity and cochlear implants. Nature 409:149-150.

Litovsky RY, Jones GL, Agrawal S, van Hoesel R (2010) Effect of age at onset of deafness on binaural sensitivity in electric hearing in humans. J Acoust Soc Am 127:400-414.

Long CJ, Eddington DK, Colburn HS, Rabinowitz WM (2003) Binaural sensitivity as a function of interaural electrode position with a bilateral cochlear implant user. J Acoust Soc Am 114:1565-1574.

Majdani O, Leinung M, Rau T, Akbarian A, Zimmerling M, Lenarz M, Lenarz T, Labadie R (2008) Demagnetization of cochlear implants and temperature changes in 3.0T MRI environment. Otolaryngol Head Neck Surg 139:833-839.

McAlpine D (2005) Creating a sense of auditory space. J Physiol 566:21-28.

McAlpine D, Martin RL, Mossop JE, Moore DR (1997) Response properties of neurons in the inferior colliculus of the monaurally deafened ferret to acoustic stimulation of the intact ear. J Neurophysiol 78:767-779.

Moore JK (2000) Organization of the human superior olivary complex. Microsc Res Tech 51:403-412.
Mower GD (1991) The effect of dark rearing on the time course of the critical period in cat visual cortex. Dev Brain Res 58:151-158.

Patrick JF, Busby PA, Gibson PJ (2006) The development of the Nucleus Freedom Cochlear implant system. Trends Amplif 10:175-200.

Poon BB, Eddington DK, Noel V, Colburn HS (2009) Sensitivity to interaural time difference with bilateral cochlear implants: development over time and effect of interaural electrode spacing. J Acoust Soc Am 126:806-815.

Popescu MV, Polley DB (2010) Monaural deprivation disrupts development of binaural selectivity in auditory midbrain and cortex. Neuron 65:718-731.

Propst EJ, Papsin BC, Stockley TL, Harrison RV, Gordon KA (2006) Auditory responses in cochlear implant users with and without GJB2 deafness. Laryngoscope 116:317-327.

Salloum CA, Valero J, Wong DD, Papsin BC, van Hoesel R, Gordon KA (2010) Lateralization of interimplant timing and level differences in children who use bilateral cochlear implants. Ear Hear 31:441-456.

Schnupp JW, Carr CE (2009) On hearing with more than one ear: lessons from evolution. Nat Neurosci 12:692-697.

Schwartz IR, Higa JF (1982) Correlated studies of the ear and brainstem in the deaf white cat: changes in the spiral ganglion and the medial superior olivary nucleus. Acta Otolaryngol 93:9-18.

Silverman MS, Clopton BM (1977) Plasticity of binaural interaction. I. Effect of early auditory deprivation. J Neurophysiol 40:1266-1274.

Smith ZM, Delgutte B (2007a) Using evoked potentials to match interaural electrode pairs with bilateral cochlear implants. J Assoc Res Otolaryngol 8:134-151.

Smith ZM, Delgutte B (2007b) Sensitivity to interaural time differences in the inferior colliculus with bilateral cochlear implants. J Neurosci 27:6740-6750

Thompson SK, von Kriegstein K, Deane-Pratt A, Marquardt T, Deichmann R, Griffiths TD, McAlpine D (2006) Representation of interaural time delay in the human auditory midbrain. Nat Neurosci 9:1096-1098.

Vale C, Juíz JM, Moore DR, Sanes DH (2004) Unilateral cochlear ablation produces greater loss of inhibition in the contralateral inferior colliculus. Eur J Neurosci 20:2133-2140.

van Hoesel RJ (2004) Exploring the benefits of bilateral cochlear implants. Audiol Neurootol 9:234-236.

van Hoesel RJ (2007) Sensitivity to binaural timing in bilateral cochlear implant users. J Acoust Soc Am 121:2192-2206.

Wada S, Starr A (1989) Anatomical bases of binaural interaction in auditory brain-stem responses from guinea pig. Electroencephalogr Clin Neurophysiol 72:535-544.

Wiesel TN, Hubel DH (1963) Single-cell responses in striate cortex of kittens deprived of vision in one eye. J Neurophysiol 26:1003-1017.

Wiesel TN, Hubel DH (1965) Extent of recovery from the effects of visual deprivation in kittens. J Neurophysiol 28:1060-1072. 